\title{
SANDÁlIAS HAVAIANAS MODELO SLIM. DO PRODUTO COTIDIANO AO UNIVERSO FASHION: UM EXERCÍCIO DE ANÁLISE SEMIÓTICA
}

\section{SLIM HAVAIANAS SANDALS. A SEMIOTIC PRODUCT DAILY ROUTE TO THE FASHION UNIVERSE: A SEMIOTIC ANALYSIS EXERCISE}

\author{
Amanda Pires Machado ${ }^{1}$ \\ Juliana Floriano ${ }^{2}$ \\ Luiz Salomão Ribas Gomez ${ }^{3}$ \\ Richard Perassi Luiz de Sousa ${ }^{4}$ \\ UFSC - Universidade Federal de Santa Catarina
}

\begin{abstract}
RESUMO: O produto sandálias Havaianas desenvolveu um percurso simbólico-publicitário, assumindo a condição de produto moda praia, moda esportiva ou moda casual. O tratamento estéticoformal determinado pelo design dos modelos Havaianas Slim indica a busca por ascensão simbólica e consequente ampliação de mercado. Caracteriza também uma ampliação no posicionamento da marca, para que parte de seus produtos seja aceita e usada em situações sociais que, até recentemente, eram pouco receptivas a pessoas calçadas com sandálias de borracha. Com base em conceitos semióticos de Charles S. Peirce, este artigo indica o contraditório processo de significação expresso nos elementos
\end{abstract}

\footnotetext{
${ }^{1}$ Mestranda em Design e Expressão Gráfica pela UFSC (2010/2012), especialista em Comunicação Empresarial pela PUCPR (2009), graduada em Desenho Industrial (Habilitação em Programação Visual) pela UNIVILLE (2003). Integrante do Grupo de Pesquisa SIGMO: Significação da Marca, Informação e Comunicação Organizacional, da UFSC.

${ }^{2}$ Graduada em Design Gráfico pela UNIVILLE (2002), especialista em Gestão e Marketing de Moda pelo SENAC - Florianópolis (2009) e mestranda do Programa PósDesign.UFSC (2010-2012). Tem experiência em projetos de Identidade Visual, Editoriais e Promocionais. Atualmente presta serviços de consultoria em Marketing e Design e leciona as disciplinas de Materiais e Processos Gráficos, Projeto de Programação Visual, Análise Gráfica e Computação Gráfica no curso de Design da UNIVILLE, nas habilitações de Gráfico e Moda.

${ }^{3}$ Possui graduação em Desenho Industrial pela PUCPR (1990), mestrado em Engenharia de Produção pela UFSC (2000) e doutorado em Engenharia de Produção pela UFSC (2004). Atualmente é professor adjunto da UFSC onde coordena o Laboratório de Orientação Gráfica Organizacional - LOGO. Realizou, em 2009, Pós-Doc junto ao UNIDCOM - IADE em Lisboa com o tema 'Brand DNA'. Tem experiência na área de Design em geral, atuando principalmente nos seguintes temas: design gráfico, metodologia, branding, ensino a distância, design industrial e história em quadrinhos.

${ }^{4}$ Doutor em Comunicação e Semiótica pela PUCSP (2001), Mestre em Educação pela UFMS (1995), Bacharel em Desenho de Propaganda e Licenciado em Artes Plásticas pelo curso de Educação Artística da UFJF (1986). Atualmente, atua como professor associado da UFSC. Anteriormente, foi professor da UFMS. Tem experiência nas áreas de Artes Visuais, Design, Comunicação, Semiótica e Educação, desenvolvendo os seguintes temas: Semiótica Visual, Arte e Design, Identidade, Cultura e Comunicação das Marcas nas Organizações.
} 
visuais do modelo Slim das sandálias Havaianas. São apresentadas a contextualização, a descrição do objeto estudado, breve revisão de parte da teoria semiótica e uma reflexão sobre o processo de significação imagética do produto em estudo.

PALAVRAS-CHAVE: Produto de moda; design; promoção simbólica; leitura semiótica.

\begin{abstract}
The product Havaianas sandals developed a symbolic walk-advertising, taking the form of product beach fashion, sports fashion or casual fashion. The treatment esthetic-formal of the Havaianas Slim models indicates the search for symbolic ascent and consequent expansion of the market. Also features an increase in Brand positioning so that part of their products to be accepted and used in social situations that just recently were receptive to people wearing rubber sandals. Based on Semiotic Concepts by Charles S. Peirce, this article shows the contradictory process of meaning expressed in the visual elements of Havaianas Slim sandals. Are presented the contextualization, description of the object under study and brief review of the Semiotics Theory and a reflection about of imagery significance of the product studied.
\end{abstract}

KEYWORDS: Fashion product; design; symbols; promotion; semiotics reading.

\title{
Introdução
}

Este artigo $^{5}$ caracteriza-se como produção resultante de pesquisa teóricoaplicada, tendo como base teórica decorrente a área de Semiótica - proposta primeiramente por Charles Sanders Peirce (1839-1914) - e também estudos em teorias psicológicas da percepção.

O processo de pesquisa consistiu, primeiramente, na definição do escopo do trabalho, determinando o foco de atenção sobre o produto em estudo e desenvolvendo pesquisa exploratória, considerando-se os conceitos, as relações e as terminologias relacionadas à cultura comercial da moda. Assim, alguns indicadores conceituais, que configuram o posicionamento do objeto na cultura da moda, foram recuperados no universo noticioso. Porém isso se refere apenas à configuração do objeto de estudo em seu ambiente de valorização, sem descaracterizar o rigor acadêmico adotado na composição da conceituação teórica.

Em seguida, dedicou-se ao processo de descrição do objeto de estudo, por meio da utilização de conceitos, relações e terminologias pertinentes ao campo de estudos de Design, com ênfase nos elementos doados pela Teoria da Forma e pelos Fundamentos da Linguagem Visual. Posteriormente, foi desenvolvido um estudo e um recorte de conceitos, relações e terminologias pertinentes ao campo de estudos semióticos. Por fim, foi feita a aplicação dos conceitos no processo de reflexão sobre os elementos e os aspectos visuais do produto que aparecem como elementos simbólicos identificadores de sua condição cultural no

5 Este artigo é parte do processo de pesquisa e estudos de Semiótica aplicada em Design do Programa de PósGraduação em Design e Expressão Gráfica (PÓSDESIGN/UFSC).

Disponível em: http://seer.fclar.unesp.br/casa 
âmbito da cultura comercial contemporânea, considerando-se especialmente os valores da moda e do mercado fashionista. ${ }^{6}$

O produto sandálias Havaianas é constantemente apresentado como modelo de sucesso no gerenciamento de marca no mercado nacional e internacional. Por ser um tema bastante explorado e considerando-se que a leitura semiótica foca prioritariamente o objeto em estudo, apresenta-se resumidamente a questão assinalando uma palestra de 2006 que, na época, repercutiu nos sítios de moda e de marketing, como o sítio Chic, de Glória Kalil (2006), e o sítio Mundo do Marketing (2006), entre outros.

A palestra tratou do case Havaianas no evento Fashion Marketing (2006). Dois funcionários da empresa SÃO PAULO ALPARGATAS S.A., o diretor de comunicação Rui Porto e a consultora de comércio exterior Ângela Hirata, apresentaram o percurso de sucesso das sandálias de borracha que, primeiramente, a partir de 1962, eram destinadas aos consumidores brasileiros de baixa renda e, posteriormente, tornou-se um produto requerido e vendido como artigo de moda em pelo menos sessenta países do mundo.

Os resultados foram indicados como decorrentes de altos investimentos em estratégias gerais de marketing e processos específicos de comunicação. Isso ocorre até os dias atuais porque, em todo o tempo, o noticiário ou a publicidade relaciona as sandálias Havaianas com eventos, personalidades ou ocasiões de glamour. Contudo o foco das ações de marketing e publicidade é centrado nas características fundamentais do produto.

De acordo com Kalil (2006), na época, o diretor de comunicação afirmou que o desafio ao produto é "mudar sem mudar", porque esse não poderia perder sua "essência", caracterizada como sandálias de borracha e sandálias de dedo. "Tem que bater o olho e ver que é uma Havaiana" (PORTO apud KALIL, 2006).

Sob o aspecto da significação, entretanto, o percurso mercadológico das sandálias Havaianas indica também um percurso evolutivo de significação, passando de marca popular de baixo preço para marca de moda. A Teoria Semiótica define como signo tudo o que está no lugar de alguma coisa como seu representante (PEIRCE, 2007); atualmente, as sandálias Havaianas são signos que representam e expressam a moda que, por si só, é um fenômeno intangível.

Como possibilidades de interpretação, os objetos ou produtos representam sentimentos ou conceitos na mente daqueles que os observam. Portanto o que é proposto, a seguir, é uma reflexão sobre as conceituações possíveis, que são relacionadas a um produto específico da área de Moda, ou seja, as sandálias Havaianas modelo Slim, cujo significado do nome pode ser imediatamente relacionado com os termos "fino" e "elegante".

Além de sua função prática, que é proteger os pés no uso diário, o produto sandálias, que, durante muito tempo, foi signo de informalidade e despojamento, é agora apresentado como signo de moda, inclusive sendo indicado para ocasiões que requerem, tradicionalmente, o uso de produtos de maior formalidade. Essa ruptura proposta na tradição é justificada pelo caráter fashion do produto de marca. Pois, de maneira geral, fashion é o que está na moda. Mas, de modo específico, fashion é aquilo que expressa inovação e vira tendência, movimentando os costumes e ditando a moda, porque tem o poder de influenciar o público. Essa influência é disseminada, primeiramente, junto aos setores especializados, que são "formadores de opinião".

A marca comercial Havaianas, que se expressa por meio de suas sandálias, requer para seu produto o direito de determinar tendências, subvertendo a tradição. Por isso,

6 " 'Fashionista' é a pessoa que está intimamente envolvida com a moda, que segue tendências." (GLOSSÁRIO DA MODA, 2010, p. 1). Assim, considera-se fashionista o mercado que se dirige ao público composto por pessoas com essas características.

Disponível em: http://seer.fclar.unesp.br/casa 
além do que é indicado no objeto de estudo, que são as sandálias modelo Slim, dois anúncios televisivos independentes, veiculados no ano de 2010, corroboram esse argumento, desenvolvendo um mesmo conceito para compor simbolicamente o uso do produto nos ambientes e momentos sociais.

O primeiro anúncio televisivo da nova campanha ${ }^{7}$ Havaianas estreou no mês de agosto de 2010. No comercial, o roteiro é desenvolvido apresentando-se, do começo ao fim do anúncio, uma fila de pessoas jovens esperando para entrar em um clube noturno. Há um grupo de amigos e todos se apresentam bem arrumados, com roupas sociais, e calçando sandálias Havaianas. Já nos primeiros instantes, alguém representando o segurança do clube, avisa que não é possível entrar de havaiana. O líder do grupo de amigos argumenta que sempre veio ao lugar de Havaianas. Em seguida, o segurança desfaz o engano, dizendo que os amigos podem entrar com as sandálias Havaianas, porque ele está se dirigindo a outra pessoa. Então, o segurança aponta para o fim da fila, de onde aparece inconformado um homem fantasiado de dançarina havaiana.

O segundo anúncio televisivo mostra uma jovem que se arruma para sair acompanhada à noite e vai ao encontro de seu acompanhante que a espera do lado de fora da casa, junto ao carro. Ao perceber que a jovem está calçando sandálias Havaianas, o acompanhante questiona sua aparência, considerando o calçado inadequado para a ocasião. Em seguida, depois de afirmar que irá fazer uma troca, a jovem retorna ao seu quarto e telefona para alguém. A última cena do anúncio mostra a jovem relatando ao acompanhante que foi feita a troca. No mesmo instante, outro carro estaciona no local, e a jovem se afasta para se reunir ao novo acompanhante, confirmando que houve a troca de acompanhante em vez da troca de calçado.

As mensagens dos anúncios televisivos confirmam a intenção dos anunciantes da marca de ampliar o uso do produto sandálias, ocupando um espaço que, primeiramente, era dominado por sapatos sociais e, posteriormente, foi também ocupado por calçados esportivos, popularmente conhecidos como tênis. Porém a atual campanha da marca Havaianas busca dividir ainda mais o espaço da moda social, ocupando-o também com suas sandálias.

\section{Características do produto que identificam a marca}

As informações deste item foram pesquisadas no sítio da marca Havaianas na internet (HAVAIANAS, 2010). Assim como o produto, o sítio pertence ao grupo SÃO PAULO ALPARGATAS S.A. O produto sandálias Havaianas foi criado em 1962, sob inspiração de um modelo de sandálias japonesas denominado Zori, confeccionado com tiras de tecido e solado de palha de arroz. Por isso, em todos os modelos, a parte superior do solado das sandálias Havaianas apresenta uma textura que imita a aparência dos grãos de arroz. Esse é o registro da inspiração de origem, como parte característica das sandálias Havaianas que, desde o início, foram produzidas em borracha. Por outro lado, o nome que marca o produto é relacionado ao Havaí, local geográfico divulgado, na época, como um paraíso de sol e mar, frequentado por pessoas norte-americanas, ricas e famosas, que passavam suas férias naquele lugar.

As campanhas publicitárias demarcaram a evolução do posicionamento da marca no mercado, que alteraram parcialmente as características físicas e simbólicas do produto. Por exemplo, os slogans da década de 1970 assinalavam o sucesso do produto de acordo com suas qualidades tangíveis, anunciando que "as Havaianas não deformam, não

7 A campanha foi criada pelo redator Gustavo Sarkis e o diretor de arte Renato Fernandez, sob direção de Marcello Serpa. Os filmes foram produzidos pela empresa Cine e dirigidos por Clovis Mello.

Disponível em: http://seer.fclar.unesp.br/casa 
soltam as tiras e não têm cheiro". Esse sucesso atraiu o interesse da concorrência em produzir calçados similares, obrigando que a marca prevenisse os consumidores com o slogan: "Havaianas. As legítimas."

A década de 1980 foi de expansão do produto, foram vendidas 80 milhões de sandálias, ${ }^{8}$ configurando um posicionamento muito popular como produto de baixo custo. $\mathrm{Na}$ década de 1990, a marca propõe uma grande mudança no seu posicionamento, passando a considerar positivamente a utilização do produto por pessoas de todas as classes sociais. "Havaianas: todo mundo usa" foi o slogan adotado na ocasião, como parte de uma campanha com a participação de artistas conhecidos da televisão brasileira. A relação com celebridades, que assumiam e referendavam o uso do produto, definiu o reposicionamento da marca.

Os fatos de marketing que consolidaram a relação entre as sandálias Havaianas e as celebridades ocorreram nas cerimônias de entrega da premiação do cinema norteamericano, o Oscar. No ano de 2003, cada profissional indicado aos prêmios recebeu sandálias Havaianas de presente. Em 2004, em parceria com a joalheria H. Stern, foi lançado um modelo de sandálias Havaianas com diamantes. Em 2006, houve o lançamento do modelo Slim, que é objeto deste estudo, esse modelo se diferenciava ao apresentar formas mais delicadas, indicando seu direcionamento comercial ao público feminino.

\section{Elementos da teoria semiótica peirceana}

A palavra semiótica advém do termo grego semeion, que significa signo. Por isso, o nome Semiótica é atribuído à Teoria Geral dos Signos, como campo de estudos lógicos que pretende estudar e categorizar os signos. No Brasil, há diversos autores que estudam ou aplicam os conceitos de semiótica, entretanto, Lucia Santaella é pesquisadora mais conhecida na área. Neste texto, considera-se, especialmente, o livro Semiótica aplicada (SANTAELLA, 2006), porque relaciona as áreas de semiótica e design. A mesma relação é estabelecida por Lucy Niemayer (2007) no livro Elementos de semiótica aplicados ao design.

Niemeyer (2007) e Santaella (2006) explicam que o signo é tudo o que está no lugar de alguma coisa ausente, passando a representá-la. Nas palavras de Peirce (2007, p. 47), "para que algo possa ser um Signo, esse algo deve 'representar', como costumamos dizer, alguma outra coisa chamada seu objeto". O signo é composto como uma tríade com os seguintes elementos: (1) representâmen; (2) objeto, e (3) interpretante. A parte perceptível do signo é o representâmen, sendo esse a coisa real ou imaginária que é percebida e colocada no lugar da outra coisa representada. O objeto do signo é a coisa real ou imaginada que é representada ou referenciada pelo representâmen do signo. $\mathrm{O}$ interpretante é a relação mental estabelecida entre o signo percebido ou representâmen e o objeto do signo, que é referido e representado. Com relação ao signo, esse interpretante é sua significação (NÖTH, 1996).

Para Peirce (2007), semiose é a "ação do signo", relacionando representâmen, objeto e interpretante, no processo de percepção e interpretação desenvolvido na mente ou consciência. O processo de percepção e interpretação de um objeto ou fenômeno implica uma fenomenologia ou estudo dos fenômenos. A fenomenologia proposta por Peirce é uma quase ciência (SANTAELLA, 2006), que prevê três categorias perceptivo-interpretativas: (1) primeiridade, (2) secundidade, e (3) terceiridade.

8 Atualmente, as sandálias da marca Havaianas participam de $80 \%$ do mercado brasileiro de chinelos de borracha, comercializando cerca de 162 milhões de sandálias anualmente. As exportações chegam a 22 milhões de pares (HAVAIANAS, 2010). 
As sensações, os sentimentos e as impressões subjetivas em geral que são produzidas na mente caracterizam os elementos de primeiridade. A secundidade é caracterizada quando a mente se dá conta de que essas sensações e impressões são estimuladas por algo que é externo à própria mente. As associações decorrentes das relações estabelecidas entre as sensações e impressões subjetivas de primeiridade e as percepções de secundidade mediadas por processos culturais caracterizam a terceiridade.

Há diferentes relações que determinam a associação entre o representâmen e o objeto do signo. Isso estabelece as classificações do signo como: ícone, índice ou símbolo, conforme são apresentados na segunda tricotomia ou série de três da teoria peirceana. A primeira tricotomia apresenta três classificações do signo: quali-signo, sin-signo e legi-signo, de acordo com o tipo de representâmen que é apresentado. A terceira tricotomia indica outras três classificações do signo: rema, dicente e argumento, de acordo com o tipo de interpretante que é produzido (NÖTH, 1996; LUCY, 2007; SANTAELLA, 2006).

Neste estudo, entretanto, o escopo adotado enfoca o relacionamento entre os representâmens e os objetos do signo, privilegiando a segunda tricotomia peirceana. De modo geral, um ícone é o tipo de signo que se relaciona com seu objeto por analogia ou semelhança. Um índice é o tipo de signo que se relaciona com seu objeto por contiguidade material, como na relação entre a parte e o todo. Um símbolo é o tipo de signo que se relaciona com seu objeto por meio de associações convencionais.

As situações e relações que exemplificam a teoria são apresentadas em seguida, uma vez que os conceitos propostos serão aplicados no processo de reflexão sobre as significações das sandálias Havaianas Slim.

\section{As sandálias Havaianas Slim como signo fashion}

O modelo Slim das sandálias Havaianas apresenta um tratamento metalizado na superfície de suas tiras de borracha (Figura 1B), participando da diversificação da linha de produtos da marca que, atualmente, oferece diversos modelos do mesmo produto, buscando atender diferentes segmentos do público.

Há modelos mais coloridos, outros mais arrojados e com adereços. São também produzidos modelos personalizados ou destinados a eventos específicos. Porém são mantidas as características básicas que denotam e identificam o produto, são determinadas pelo uso da borracha como matéria-prima e pela sua forma específica que, popularmente, caracteriza o produto como "chinelo de dedo". A versão mais tradicional (Figura 1A) apresenta tiras em formato "V" e, em todas as versões, são recorrentes as mesmas texturas no solado. A da parte superior é diferente da textura da parte inferior, que apresenta frisos antiderrapantes.

A morfologia das sandálias Havaianas e o material utilizado na fabricação, de modo geral, sugerem descontração e informalidade social (Figuras 1A e 1B). Do ponto de vista semiótico, o ícone percebido ou experimentado promove sensações e sentimentos, os quais são relacionados ao relaxamento, à liberdade, ao conforto e ao despojamento que, culturalmente, são associados a conceitos, indicando o produto como símbolo de descontração e informalidade social.

A aceitação de que a morfologia das sandálias compõe um ícone de liberdade, com conforto e relaxamento, requer a compreensão de que o valor simbólico das coisas percebidas ou experimentadas é determinado por convenções culturais, as quais associam as coisas entre si. Por exemplo, as sandálias de borracha são convencionalmente associadas à praia, ao banho e a outras situações que envolvam água. Mas convenções desse tipo decorrem 
primeiramente de sensações e sentimentos, pois, calçando-se sandálias de borracha, as sensações vivenciadas em decorrência do contato com água em abundância são agradáveis, especialmente, quando comparadas às sensações decorrentes do contato com água em abundância com sapatos de couro ou tecido. Portanto a ideia de se molhar calçando sandálias de borracha costuma deixar alguém mais satisfeito, mesmo que essa pessoa não tenha vivido tal experiência, porque já existe uma associação cultural entre água e sandálias de borracha.

Considerando o acervo de sensações, sentimentos, ideias e convenções culturalmente acumuladas e confirmando sua origem popular fora do contexto cultural da moda, as sandálias Havaianas (Figura 1A), primeiramente, mostram-se como um produto típico para o uso doméstico ou informal, seja para os momentos de trabalho, de repouso ou de lazer.

As sensações decorrentes da experiência icônica, sensível-afetiva proporcionam sentimentos de liberdade, praticidade, despojamento, informalidade e conforto. Quando essas sensações e sentimentos são relacionados culturalmente ao uso, o signo é interpretado como símbolo de calçado informal e confortável, porque se opõe ao rigor desconfortável dos calçados sociais que, tradicionalmente, são formais, fechados, sisudos e, geralmente, ostentam uma aparência mais luxuosa.

O modelo Slim que, de modo geral, confirma em grande parte a significação proposta para as sandálias Havaianas, apresenta-se, entretanto, com algumas características diferenciadas, que ampliam e complicam o processo de significação. O modelo é signo icônico dos calçados do tipo sandálias, mas apresenta algumas características incomuns, configurando um estilo próprio e acrescentando ao signo "sandálias" adjetivações simbólicas de elegância e luxo.

As características formais incomuns do modelo Slim indicam as sandálias nesse estilo como símbolo fashion, considerando o adjetivo no sentido específico como atributo daquilo que dita moda. Para tanto, além de formas mais delicadas, elegantes e femininas, o modelo também apresenta tiras com tratamento metalizado como parte das sandálias Havaianas com brilho. A imagem a seguir (Figura 1B) representa o modelo Slim com tiras douradas e, em comparação ao modelo tradicional (Figura 1A), houve alterações de configuração, volume, brilho e cor, resultando em diferenças de proporção e dinamismo.

Com relação ao modelo tradicional, a diferença de proporcionalidade do modelo Slim promove sensações e sentimentos indicadores dos atributos simbólicos de delicadeza, elegância ou refinamento, indicando também uma forma mais dinâmica. O efeito de brilho decorrente do tratamento metalizado das tiras sugere superfícies mais polidas, alterando o efeito original da superfície de borracha e configurando um produto de aparência supostamente luxuosa.
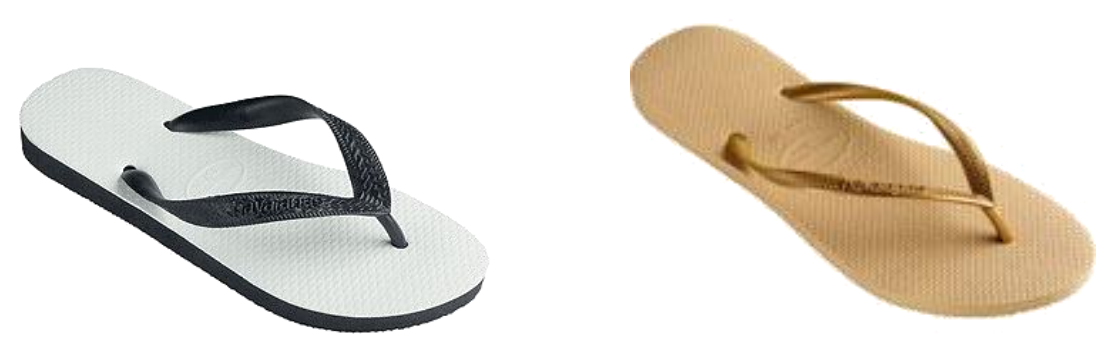

Figura 1A: Sandálias Havaianas Modelo Tradicional Figura 1B: Sandálias Havaianas Modelo Slim. Fonte: www.havaianas.com 
Sob o aspecto prático-funcional, os calçados são produzidos com o objetivo de proteger os pés, sendo classificados por sua utilização e formato. Os chinelos ou sandálias também oferecem proteção, entretanto protegem a planta dos pés deixando mais ou menos expostas as partes superiores. Por isso, as sandálias são ideais para locais quentes ou dias de calor, porque protegem os pés sem abafá-los.

Há sandálias de diversos tipos, sendo que os modelos com saltos altos e finos são mais indicados para os eventos cerimoniais. Outros modelos sem saltos e confeccionados com materiais pouco nobres, como as sandálias de borracha, são tradicionalmente destinadas ao uso doméstico, ao trabalho mais rústico e aos momentos de descanso ou lazer, marcados pelo despojamento e pela informalidade.

Com exceção das sandálias femininas em couro tratado ou em outros materiais nobres e com saltos finos e altos, são os calçados clássicos, formais ou sociais, femininos ou masculinos, que se apresentam e são usados de acordo com rígidos códigos culturais de etiqueta, de vestuário e de moda cerimonial.

De maneira geral, os calçados modernos indicados como sociais ou cerimoniais apresentam algum tipo de salto físico. Isso, também, pressupõe um tipo de "salto" simbólico, estabelecendo distinção social para o usuário e atendendo aos códigos de formalidade, implicando atitudes, vestimentas e situações formais ou cerimoniais.

Há relações culturais que, tradicionalmente, associam os calçados informais, como chinelos e sapatos esportivos, a materiais como borracha, palha, tecido e couro rústico, entre outros. Esses calçados são usais em situações descontraídas, mesmo que sejam situações de trabalho, mas também podem atender a alguma outra formalização, que é determinada por códigos esportivos ou de moda casual.

As principais diferenças entre os calçados formais e os informais (Figura 2) estão relacionadas à relação entre forma e função. Primeiramente, um calçado informal propõe, em sua morfologia e nos materiais, o uso casual ou não cerimonial em situações de descanso ou lazer e em certos tipos de trabalho. Um calçado formal é utilizado em situações cerimoniais, exibindo morfologia com características específicas e materiais mais requintados. Em princípio, as sandálias Havaianas apresentam características de calçados informais. Mas as sandálias Havaianas no modelo Slim apresentam aspectos estéticos diferentes do modelo tradicional, estabelecendo a ambiguidade entre a configuração informal e a aparência luxuosa e formal, que é sugerida pelo tratamento brilhante nas tiras de borracha e pelo tom sóbrio da base de borracha, que combina com a tonalidade das tiras, oferecendo um fundo neutro e com tonalidade coerente para os detalhes brilhantes (Figura 1B).

O modelo Slim apresenta uma estrutura bastante semelhante ao modelo tradicional (Figura 1A). As diferenças sutis são determinadas pelo formato mais delgado do solado e por tiras mais finas; o produto como um todo apresenta um aspecto mais delicado e sofisticado. O tratamento brilhante das tiras remete ao requinte e ao luxo, estabelecendo um paradoxo entre os sentidos de informalidade e formalidade. $O$ brilho dourado é, tradicionalmente, relacionado aos eventos noturnos e à riqueza, ao luxo, ao poder e à ostentação da nobreza. Nestes anos 2000, o uso do dourado no vestuário e, especialmente, nos acessórios femininos, inclusive, aparece constantemente em situações diurnas e bastante informais.
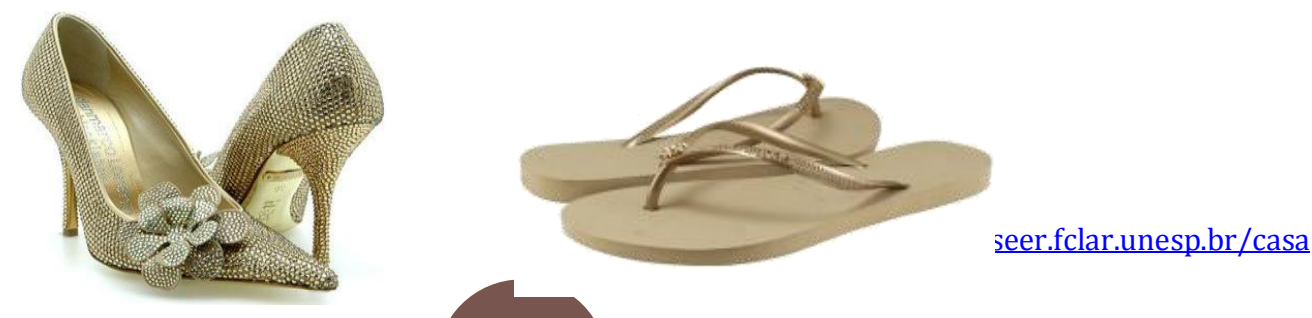
Figura 2 - Calçado formal, luxuoso e cerimonioso, e sandálias Havaianas Slim, informais e luxuosas. Fonte: Web, 2010.

Com seus diversos modelos, as sandálias Havaianas transitam em diferentes ambientes e situações, atendendo a necessidades essencialmente práticas, ordinárias ou casuais e, também, atuando como elementos simbólicos, que expressam diferentes estilos de acordo com as características do modelo e as situações de uso.

Jones $(2007$, p. 24) reuniu conceitos sobre a cultura da vestimenta, indicando as funções do vestuário. Em princípio, há funções práticas, morais e estético-simbólicas, que assinalam características individuais ou sociais. Esses usos podem ser estendidos a outros itens, como acessórios e, especialmente, calçados. Assim, consideram-se critérios de utilidade, decência ou indecência, envolvendo o erotismo, e também de ornamentação, de diferenciação simbólica, filiação social, autoaprimoramento psicológico ou de atualidade.

Entre os aspectos morais, a decência é decorrente da adequação exigida pela sociedade de que o indivíduo cubra sua nudez e regule suas atitudes para manter os sistemas de ambiência e convívio em níveis considerados civilizados. Por sua vez, os indivíduos e a própria sociedade escolhem ambientes, momentos e situações permissivas, nas quais os atrativos físico-sexuais são realçados, com a exibição e ornamentação de partes do corpo, implicando a erotização do convívio pessoal e social, dando oportunidade a expressões de criatividade e individualidade (JONES, 2007).

Praticamente todas as funções assinaladas podem ser consideradas no conjunto de produtos indicados como sandálias Havaianas. Há que se observar, entretanto, que as peculiaridades associadas à filiação social e diferenciação simbólica estão mais relacionadas a situações de uso do que aos produtos em si mesmos. Isso deve ser observado porque as sandálias Havaianas participam do seleto grupo de produtos que mantêm seu valor de marca e se apresentam como símbolos de distinção, apesar de serem acessíveis a todos os tipos de público, como ressalta o slogan: "Havaianas, todo mundo usa".

Isso estabelece o paradoxo, sugerindo a alta eficiência comercial do produto, que é apresentado e aceito, ao mesmo tempo, como algo distintivo e popular. Todos podem usar ou consumir, e o uso ou consumo engrandece a todos. Pode-se imaginar que os mais humildes sintam-se valorizados ao terem acesso a um produto valorizado e consumido por representantes das classes socialmente mais elevadas. Por sua vez, ao usar um produto popular, as pessoas ricas e famosas se apresentam como indivíduos despojados e naturalmente elegantes dentro de seus carros luxuosos e dos ambientes requintados.

Atualmente, os paradoxos aparecem constantemente nas propostas de moda, por meio de conjunções inusitadas, combinando signos de luxo, sejam ícones ou índices, com materiais e elementos populares Alguns produtos de moda resultam da combinação de materiais, formas e peças clássicas ou antigas com elementos modernos, apresentando conjuntos que reúnem, por exemplo, couro e plástico cromado, colorido ou transparente, entre outras inúmeras possibilidades.

As sandálias Havaianas modelo Slim apresentam índices de borracha e de sandálias que, culturalmente, são percebidos como símbolos populares. Esses símbolos são relacionados, no produto, com o símbolo de luxo expresso pelo ícone dourado determinado pelo tratamento dourado das tiras. Assim, as contradições são vivenciadas já no âmbito da primeiridade, com sensações contraditórias, devido aos sentimentos de informalidade e de luxo. A percepção do objeto externo estabelece a secundidade, indicando-o como índice de Disponível em: http://seer.fclar.unesp.br/casa 
borracha e também de sandália, porque o objeto estudado é parte do amplo conjunto de sandálias e atua como representação desse conjunto. No âmbito simbólico da terceiridade as sandálias em estudo, Havaianas modelo Slim, são símbolos de calçados fashion, que expressam a ambiguidade entre a tradição cerimoniosa da cor dourada e a informalidade das sandálias de borracha e, atualmente, a percepção dessa contradição é um signo considerado como símbolo de uma tendência do momento.

No universo da moda, uma das abordagens de segmentação de mercado divide os consumidores por estilos, que podem ser (1) tradicional, (2) fashion e (3) vanguarda. De acordo com Treptow (2007), considera-se que os estilos demarcam diferentes hábitos de consumo: o estilo tradicional é basicamente acomodado, indiferente à moda; o estilo fashion caracteriza o público de moda, que é atento às novidades, e o estilo vanguarda é determinado por pessoas rebeldes que gostam de se sentirem diferentes.

As sandálias Havaianas modelo Slim demarcam o estilo fashion, porque derivam de um modelo clássico (tradicional), expressando tendências da moda. Mas, não propõem inovações vanguardistas, uma vez que, com relação a sandálias Havaianas, vanguarda foi a adoção social do modelo tradicional, como expressão de valores jovens que propunham a "sociedade alternativa", ainda na década de 1970.

\section{Considerações finais}

O exagero, a ambiguidade e a informalidade caracterizam a moda atual, que se expressa em produtos percebidos como fashion. O sentido fashionista dos produtos é determinado por sentimentos específicos, que são despertados no observador-consumidor. Todavia há a identificação dos aspectos e elementos que caracterizam e passam a simbolizar os produtos fashion do momento. Entre esses aspectos, aparece a contradição, o paradoxo ou a ambiguidade percebida nas sandálias Havaianas Slim.

Por conveniência, a contradição estético-simbólica está alinhada às estratégias de mercado, que visam sobrevalorizar o produto, de acordo com a sua condição de signo fashion. Assim, a política de preço dos produtos sandálias Havaianas varia de acordo com seu posicionamento fashion, sendo que os lançamentos ou os modelos mais atuais são comercializados com preços diferenciados com relação ao modelo básico ou tradicional.

Além de poder comercializar seus produtos com preços mais elevados, há indícios de que a estratégia adotada pela empresa ALPARGATAS S.A., ao configurar o posicionamento das sandálias Havaianas Slim, também busca ampliar o seu mercado de atuação e consumo. Para tanto, o modelo em estudo evidencia o investimento na diversificação de modelos da marca, compondo uma cultura da variedade de expressões ou estilos sobre um mesmo tema básico. Isso amplia e diversifica os ambientes de consumo dos produtos Havaianas.

Como foi proposto, o valor simbólico do objeto de moda propicia a venda por um preço superior ao que poderia ser cobrado exclusivamente por seu valor de uso. As sandálias Havaianas Slim são afetivamente percebidas como detentoras de valores expressivos emocionalmente associados aos sentimentos fashionistas. Os sentimentos decorrem das sensações decorrentes da percepção do produto. Todavia, para que haja essa sensibilização, é necessário que o observador-consumidor seja esteticamente educado para se sensibilizar com os apelos estéticos do produto.

A educação estético-estilística do observador-consumidor é desenvolvida dentro de um amplo espectro cultural, em que as opiniões e as ilustrações apresentadas por estilistas, críticos e fashionistas são repercutidas em reportagens e propagandas na mídia 
especializada e na mídia em geral. Os exemplos disso foram anteriormente apresentados na descrição das propagandas televisivas, que estão sendo veiculadas pela marca Havaianas.

A mídia em geral foi expandida e diversificada com o advento e a consolidação da internet e de suas redes sociais. No ambiente midiático, as informações se multiplicam em blogs referentes à moda, de maneira oficial ou casual, e os modelos se cristalizam na recorrência sobre os mesmos aspectos, tornam-se critérios da moda, que são entendidos por alguns e assimilados intuitivamente pela maioria.

O processo estético-simbólico de divulgação de tendências e modelos é reforçado pela adesão das marcas que passam a distribuir produtos com características da moda. Isso propõe uma dupla via de reforços positivos, porque as marcas confirmam e validam a moda e essa valoriza os produtos e suas marcas. Simbolicamente, a mídia e as marcas confirmam certas tendências formais e comportamentais como características de moda, indicando seu status específico e distintivo, como código de usos e costumes. Por outro lado, as marcas que se posicionam em conjunção com a moda recebem, também, atributos simbólicos, passando a ostentar status diferenciado aos olhos do observadorconsumidor, que se dispõe a pagar mais para usufruir desse benefício, associando sua personalidade à imagem da marca.

Os símbolos da moda são, portanto, percebidos sob aspectos afetivos e cognitivos, cuja identificação e ação decorrem da ascensão bem sucedida da condição de produto de uso para a concepção de produto simbólico. Em seu design, as sandálias Havaianas Slim receberam tratamentos diferenciados, em suas formas e cores, e são divulgadas na mídia como produtos simbolicamente apropriados para se transitar em ambientes que, tradicionalmente, eram restritivos às sandálias de borracha, porque requeriam outros tipos de calçados considerados mais distintos ou sociais.

\section{REFERÊNCIAS}

ALVES, M.; ARRUDA, S. Como elaborar um artigo científico. UFSC - Universidade Federal de Santa Catarina. Disponível em: http://www.bu.ufsc.br/design/ArtigoCientifico.pdf. Acesso em: 18 de mar. 2010.

HAVAIANAS. Portal disponível em [www.havaianas.com] acessado em 22 de setembro de 2010.

JAPIASSU, H.; MARCONDES, D. Dicionário Básico de Filosofia. Rio de Janeiro: Jorge Zahar, 1990.

JONES, S. J. Fashion design: manual do estilista. São Paulo: Cosac Naify, 2007.

KALIL, G. Havaianas: o sucesso não foi sorte, mas investimento em marketing. In: Chic (2006).Disponível em: http://chic.ig.com.br/materias/365501-366000/365632/365632 1.html. Acesso em: 22 de set. 2010.

LAKATOS, E; MARCONI, M. Metodologia do Trabalho Científico. São Paulo: Atlas, 2009.

MUNDO DAS MARCAS. Disponível em: www.mundodasmarcas.blogspot.com. Acesso em: 22 de set. 2010.

NIEMEYER, L. Elementos de semiótica aplicados ao design. Rio de Janeiro: 2AB, 2007.

NÖTH, W. A Semiótica no Século XX, São Paulo: Annablume, 1996. 
CASA, Vol.10 n.1, julho de 2012

PEIRCE, C. S. Semiótica. São Paulo: Perspectiva, 2007.

SANTAELLA, L. Semiótica aplicada. São Paulo: Cengage Learning, 2006.

TREPTOW, D. Inventando moda: planejamento de coleção. Brusque, SC: D. Treptow, 2007.

Recebido em: 23/06/11

Aprovado em: 23/10/11 